\title{
A mathematical model for the product mixing and lot-sizing problem by considering stochastic demand
}

\author{
Dionicio Neira Rodado ${ }^{a}$, John Willmer Escobar ${ }^{b *}$, Rafael Guillermo García-Cáceres ${ }^{c}$ and Fabricio Andrés \\ Niebles Atencio ${ }^{a}$
}

${ }^{a}$ Departamento de Ingeniería Industrial, Universidad de la Costa. Calle 58 \# 55 - 66. Barranquilla, Colombia

${ }^{b}$ Departamento de Ingeniería Civil e Industrial, Pontificia Universidad Javeriana. Calle 18 No 118-250, Cali (Colombia)

${ }^{c}$ Profesor Investigador, Universidad Antonio Nariño, Bogotá, Colombia. Colombia

\begin{tabular}{l}
\hline C H R O N I C L E \\
\hline Article history: \\
Received April 262016 \\
Received in Revised Format \\
August 162016 \\
Accepted September 142016 \\
Available online \\
September 142016 \\
\hline Keywords: \\
Lot Sizing \\
Product-mix planning \\
Stochastic demand \\
EVA \\
Sample average approximation
\end{tabular}

\section{Introduction}

It is a huge challenge for companies to reach strategic decisions related to the production system. Some of the most difficult decisions are the definition of the mix of products, the determination of the lot size for each item, and the scheduling for a monthly view. Currently, these decisions are relevant, especially when the life cycle of products is short and customers ask for more customized products. Indeed, the companies must satisfy the demand of the customers of specific products with eminent quality and short delivery times. The decision making process becomes very difficult due to the fact that companies usually do not have the tools to solve the problem of lot sizing and product-mix planning by considering the maximization of the profit of the companies. This decision affects both, the productivity and the

* Corresponding author

E-mail: jwescobar@javerianacali.edu.co (J. W. Escobar)

(C) 2017 Growing Science Ltd. All rights reserved. doi: $10.5267 /$ j. ijiec.2016.9.003

\begin{abstract}
The product-mix planning and the lot size decisions are some of the most fundamental research themes for the operations research community. The fact that markets have become more unpredictable has increaed the importance of these issues, rapidly. Currently, directors need to work with product-mix planning and lot size decision models by introducing stochastic variables related to the demands, lead times, etc. However, some real mathematical models involving stochastic variables are not capable of obtaining good solutions within short commuting times. Several heuristics and metaheuristics have been developed to deal with lot decisions problems, in order to obtain high quality results within short commuting times. Nevertheless, the search for an efficient model by considering product mix and deal size with stochastic demand is a prominent research area. This paper aims to develop a general model for the product-mix, and lot size decision within a stochastic demand environment, by introducing the Economic Value Added (EVA) as the objective function of a product portfolio selection. The proposed stochastic model has been solved by using a Sample Average Approximation (SAA) scheme. The proposed model obtains high quality results within acceptable computing times.
\end{abstract}

C 2017 Growing Science Ltd. All rights reserved 
profitability of them. The problem of product mixing and lot sizing has been commonly addressed by considering the maximization of profit and the maximization of incomes. On the other hand, some authors have considered the minimization of costs. The decision of lot sizing a mix product is a key success for the worldwide companies. This decision involves the participation of different areas of the company such as sales, supplies and production and marketing. In particular, each area tries to impose its arguments in order to increase or decrease the lot size and to include or eliminate products from the companies' portfolio achieving greater or lesser amount of finished products or raw materials. We have proposed a Stochastic Mixed Integer Linear Programming Model (SILP) for the product mixing and lot-sizing problem. The decisions of the stochastic model are defined in two steps by considering variability of the demand. It is first proposed as the objective function of the SILP model, the maximization of EVA, and the latter is defined as the economic value added generated by the company. The solution strategy used for the SILP model solution is known as Sample Average Approximation (SAA). This methodology has been proposed by Kleywegt et al. (2002) and uses a scheme of sample averages by Monte Carlo Simulation for stochastic linear programming problems.

The main contribution of this paper is the mathematical construction of the proposed SMILP model by considering the EVA as the objective function. In addition, the paper extends the literature of mathematical modeling applied to the problem of lot sizing and product mixing by considering variability of demand. In particular, we seek to assess the applicability and effectiveness of a stochastic linear model for the considered problem. In Section 2, the literature review of topics related to the paper with stochastic elements is introduced. In Section 3, the proposed mathematical model is presented. The solutions strategy SAA is presented in Section 4. Finally, computational results and conclusions are given in Section 5.

\section{Literature Review}

\subsection{Economic Value Added}

Although Marshall (1980) stated the principles of EVA almost 100 years before, this financial measure began to be widely carried out just until the decade of 1980. This financial measure tries to define a relationship between the cost of the investment in the company and its minimum expected profit. The main goal of any company is to generate economic wealth in order to give out the profits, increment the value of shares and reinvest in economic projects. Indeed, the generation of economic value, will result in the wellbeing of society, shareholders and employees. A company generates economic value only if the return over the investment is greater than the cost of capital. On the other hand, if the return on investment is less than the cost of capital, the company is its destroying value. Indeed, the Economic Value Added (EVA) is the product obtained from the difference between profitability of assets and the monetary value of capital required to possess those assets. The EVA is obtained by deducting from the operational income the operational expenses, value of taxes, and the costs of opportunity of capital investment (Lin \& Qiao, 2010; Singh \& Mehta, 2012). Therefore, the productivity of all elements used to develop the entrepreneurial activity is considered in this measure. In other words, EVA is the result obtained once all the expenses and a minimum profitability expected by the shareholders have been covered (Lin \& Qiao, 2010). The EVA can be calculated as follows:

$$
\begin{aligned}
& E V A=N O P A T-(W A C C * N O A) \\
& N O A=F O A+N O W C
\end{aligned}
$$

where,

- NOPAT corresponds to the Net Operating Profits After Taxes,

- NOA corresponds to the Net Operating Assets, 
- WACC corresponds to Weighted Average Cost of Capital,

- FOA corresponds to the Fixed Operating Assets,

- $\quad$ NOWC corresponds to the Net Operating Working Capital.

The Eq. (1) calculates the difference between the return rate of capital and the cost of Weighted Average Capital Cost (WACC), multiplied by the economic value of the invested capital of the concern. NOWC depends on the mean accounts receivable, the mean accounts payable, and the mean inventory. From the Eq. (1), it is possible to infer that a company could have earnings, but they may not be adequate to obtain a positive value of EVA. According to Ray (2001), the importance of EVA in comparison with the generally accepted accounting principles stays in the fact that EVA shows in a better way the relationship between productivity and the financial wellbeing of the company.

\subsection{Product-mix planning and Lot Sizing}

Many researches have studied deeply the lot-sizing problem. Rizk and Martel (2001) proposed a literature review of related problems with lot-sizing decisions. In this work, it is remarked that nearly all the proposed models are based on the Economic Order Quantity (EOQ) principle or based on the Wagner and Within Model (Dynamic lot sizing). According to those authors, the lot-sizing problem (LP) can be split in two main categories: the Single Facility LP (SLP) and the Multifacility LP (MLP). In addition, both categories could be divided in the following subcategories: single item and multi-item problems, uncapacitated and capacitated problems, and single stage and multistage problems.

Single Facility LP (SLP) problems are the most studied in the literature. In this type of problem, the transportation cost is not considered. In general, this type of problem considers a multi machine or multistage facility system. The interdependency between the different facilities in the system are often not considered due to the predominant assumption that the general multifacility problem could be solved by optimizing the costs of each facility independently, and due to the difficulties of solving big size problems in real time (Rizk \& Martel, 2001, 2006). Within SLP category, it is possible to find several variants dealing with Uncapacitated Single Item Problem (Rizk \& Martel, 2001), Capacitated Single Item Problems (Haksever \& Moussourakis, 2008), Continuous Setup Lot-Sizing Problem (Karimi et al. 2003), Discrete Lot-Sizing and Scheduling Problem (Absi \& Kedad-Sidhoum, 2008) and (Van Hoesel, et al. 1994), Uncapacitated Multi-item Problems (Van Eijs et al. 1992) and Capacitated Multi-item Problems (Fleischmann, 1990). The Multi-Level Lot-sizing Problem (MLP) considers products that are manufactured through several levels, possibly involving several production/stocking points. The objective of the MLP is to determine a multi-stage production/procurement schedule, which minimizes the total cost, while known demand is fulfilled. There are two types of demand in the MLP: independent demand and dependent demand. Independent demand is activated outside the firm. Dependent demand is triggered by the production/supply required to fulfill the independent demand. Within MLP category, several variants have been proposed related to Uncapacitated Single Item Problems (Rizk \& Martel, 2001), Capacitated Single Item Problems (Rizk \& Martel, 2001) and Capacitated Multi-Item Problems (Mabin \& Gibson, 1998). The different variations of the lot sizing problems use deterministic demand to determine the optimum. The solution for these types of problems could be obtained by different techniques such as branch and bound schemes, ant colony optimization among others. Usually, the objective function is expressed as the minimization of costs or the maximization of earnings or incomes (Alejandro et al. 2013)

\subsection{Methodologies for the solution of LP problems}

Over the final 50 years, researchers have found many applications of optimization in the study of production planning and scheduling, product mix, lot sizing, and location and transportation problems. Earliest approaches have considered deterministic parameters avoiding the appropriate representation of 
realistic situations. The evolution of processors has been a relevant fact, which help researchers work with more complex models in order to represent real problems more accurately by including random parameters within mathematical models. The inclusion of variability within LP models has included higher complexity. The complexity grew exponentially, and gave an impulse to new schemes, that served to obtain faster solutions for complex problems. These new methodologies included nature-based heuristics, such as Ant Colony Optimization (ACO), Particle Swarm Optimization (PSO), Artificial Neural Networks (ANN), and Genetic Algorithms (GA). These methodologies are characterized by using one, although random, structured search approximation (Niebles-Atencio \& Neira-Rodado, 2016).

The different types of techniques to solve stochastic programming for LP problems are listed as follows: Programming with recourse, stochastic linear programming, stochastic integer programming, stochastic non-linear programming, Robust Stochastic Programming, Probabilistic Programming, Fuzzy Mathematical Programming, Flexible programming, Possibility programming, and Stochastic Dynamic Programming (Sahinidis, 2003; Ahmed et al. 2004; Su \& Wong, 2008). It is also important to point that techniques such as Sample Average Approximation (SAA) are very useful to find solutions with stochastic variables (Santoso et al., 2005; Escobar, 2012; Escobar et al., 2012; Escobar, 2009; Escobar et al., 2013; Paz et al., 2015; Mafla \& Escobar, 2015).

The proposed SAA scheme used on this paper is based on the work proposed by Kleywegt et al. (2002) and Paz et al. (2015). First, a limited sample of the lot sizing problem and configurations of the mix of products is generated; in which each of these decisions is determined from multiple random generation by using random demand scenarios and corresponding stochastic model solutions. For each scenario, the indicators proposed in Mafla and Escobar, (20015) are calculated to verify the stopping criterion, and then the procedure is repeated until the criterion is met, ensuring the selection of the best configuration.

\section{Proposed Mathematical Model}

The proposed mathematical model for the product mixing and lot sizing planning has been inspired on a company with a multistage process. Each stage of the process has different number of machines and each machine receives a different operating cost and a different speed. The statistics needed for the problem modeling such as speed of machines, standard processing times, set up times, percentage of defects, maximum sales standard deviation, are recognized. The submitted information corresponds to a four-stage production process company. This company trades its products to retail stores. The company operates with an MTS (make to stock) policy, and makes a monthly production program by placing production orders considering the projected sales and the finished inventory per item.

The following assumptions are considered for the proposed model:

- The shortage is permitted,

- Multi-product and multi-stage production process have been considered,

- Working process is not considered,

- Each product has a different proportion of defective points,

- $\quad$ Each process has a different ratio of defective items,

- The defective items imply a reprocessing time,

- No constraints of space have been considered related to raw material,

- The processing times in each stage and each machine are considered as deterministic,

- The set up times are considered deterministic,

- The demand for each item follows a normal density distribution function.

We have considered a possible portfolio of 64 items. All the info related to the items is known (the expected sales, the standard deviation of the sales, the maximum possible sales, and the monthly stationary 
index). In addition, all the information related to the process is recognized (the processing times of each item at each machine and the set up time of each machine for each particular item). Moreover, it is relevant to state that in each process, some machines are faster than others. Each of these machines has a different production rate. Indeed, each machine has a different activation cost and is able to develop a different amount of items. This situation obviously affects the financial outcomes of the company. This is a very significant issue for the formulation of the problem due to that it commonly forces to consider a great amount of variables of the type $Q_{i m}$ (quantity of product $i$ to be processed on machine $m$ ). In order to reduce the size of the problem, the proposed formulation contains average costs and speeds in each stage, which are conformed to some speed and cost correction factors depending on the machine assigned to process the items. In addition, we have considered that the company produces Ready-to-assemble furniture (RTA). Indeed, each furniture is made of a several number of pieces, which could be not assembling in the manufacturing plant. Therefore, it is assumed that a similar amount of work can be assigned to each machine in each place of the process. In the proposed model, the defective items are generated and collected in each stage, and then are reprocessed only at the conclusion of the process. The problem of the product mix planning and lot size decisions is addressed as a problem of maximization of the Economic Value Added of the company (EVA) by seeing the different stages of the process, the annual demand of the different items manufactured by the company, the total costs of the company, and the schedule of the different items. The problem of the product mix and lot size was tackled in two phases. The first phase deals with the product mix problem. The proposed model analyzes the products produced by the company and the costs of each asset. This approach leads to the maximization of the EVA of the company. The decisions of the first phase consider the selection of the products that the company must be produced and the assets (machines) that the company must use to produce the selected items. This first phase of the stochastic model was stated as the maximization of the EVA of the company. In the second phase, the selected products must be scheduled according to monthly plans and employing the selected assets in the first phase. The second phase problem is tackled as the maximization of the company's earnings. The expected results of the second phase must be the amount of product to be produced for each month.

\section{Notation of the proposed Model}

Sets

ITEM

PROCESS

MACHINES

FAMILIES

\section{Parameters}

$T A X$

$U C_{i}$

$S P_{i}$

WACC

$O P C_{j}$

$s t_{i j}$

$F O A_{m j}$

$M_{j}$

$d f f_{i j}$

$F C$

$A C$

$P S_{i}$
Portfolio of products of company, indexed by $i$

Productive process of company, indexed by $j$

Available machine in each process, indexed by $m$

Groups of items with similar characteristics (tables, libraries, etc) indexed by $f$
Tax fare $[\%]$

Cost per unit of the product $i$ [\$ / unit]

Sale price for product $i$ [\$/ unit]

Weighted average cost of capital [\%]

Overall time available in each process in the time horizon $\mathrm{T}$ [hrs]

Standard time of the product $i$ in the process $j$ [time unit]

Value of the asset (machine) $m$ of the process $j$ [\$]

Number of machines available in process $j$

Mean proportion of defectives generated in process $j$ of item $i$

Fixed costs of the company [\$]

Administration costs of the company [\$]

Potential sales of item $i$ [unit] 


\section{Variables}

$S U T_{i}$

$A R_{i}$

$A P_{i}$

$\overline{I_{l}}$

$o_{j m}$

$S U_{\text {if }}$

$y_{j m}$
Units of item $i$ considered in the final mix of the portfolio.

Accounts receivable associated with the sales of item $i$ [\$]

Accounts payable associated with the purchase of raw material for item $i$ [\$]

Mean inventory of raw materials for item $i[\$]$

Binary variable equal to 1 if the machine $m$ of process $j$ is included on the assets needs to maximize the EVA, 0, otherwise.

Sold units of item $i$ included in family $f$

Activation variable (binary) for the cost $F O A_{m j}$

The first stage maximization formulation is stated taking into account equation (1) and (2).

The objective function of the first stage is formulated as follows:

$$
\begin{array}{r}
Z(\max )=\left(\sum_{i=1}^{n}\left(S P_{i} * S U T_{i}\right)-\left(F C+A C+\sum_{i=1}^{n}\left(U C_{i} * S U_{i}\right)\right) *(1-\text { tax fare })\right. \\
-\left(\sum_{i=1}^{n} A R_{i}-\sum_{i=1}^{n} A P_{i}+\left(\sum_{i=1}^{n} \bar{I}_{i}\right)+\sum_{j=1}^{4} \sum_{m=1}^{M_{j}} F O A_{m j}\right) * W A C C
\end{array}
$$

The amount of the accounts receivable and accounts payable depends on the policies of the companies. In particular, we have considered a policy with ar days for the accounts receivable and ap days policy for the accounts payable. ar and ap are given parameters.

The average inventory of raw materials could be considered constant in time and it is determined with respect to the raw materials requirements. In the first stage, we assume that the inventory of finished product is zero, i.e. once a product is manufactured it is immediately delivered to the customer. The accounts receivable is a function of the sales and the rotation (rotation is determined as 6 times, i.e. 360 days / 60 days), assuming that all the sales have been performed by credit. The accounts payable is a function of the expenditures and the rotation, assuming that only materials expenditures have been performed by credit. Another important assumption at this point is that the fixed costs and management costs not vary or its variation is considered negligible. In addition, the total production cost considers a correction factor related with the amount of defectives that the process generates of each item. Additionally, the portion of defective items is not the same for all the items because of their complexity level, which is also the reason to work with different processes and set up times for each particular item.

The mathematical model is subject to the following constraints:

- Capacity of the different processes:

For each process, a capacity constrain is defined by the used machines. For example, in the case of the first process (sawing process) the set of constraint must be defined as:

$$
\sum_{i}\left(s t_{i 1} * \sum_{f} S U_{i f}\right) / \prod\left(1-\operatorname{deff}_{i 1}\right) \leq\left(1,5 * o_{11}+1,5 * o_{12}+0,5 * o_{13}+0,5 * o_{14}\right) * \frac{O P C_{1}}{4}
$$

This set of constraints ensure that the sum of the time needed for making the amount of the selected items must to be less than or equal to the available time of this process for each year by considering only working days. This set of constrains consider the defectives items. The right hand side of the inequality shows the overall process capacity (OPC), which is divided by the number of machines of the process (4 machines available of the sawing process) to find the capacity of one machine per year. The value of 1,5 that 
multiplies the variable $o_{11}$ indicates that the machine is $50 \%$ faster than the average speed of the process. In this case, machine number 1 of the sawing process, is $50 \%$ faster than the mean of the sawing process.

- Proportion of families of portfolio products:

This group of constraints ensures must have participation less than $30 \%$ of the sales of the company. This constraint considers that the company has six product families (tables, miscellaneous, entertainment centers, computer centers, armoires, and libraries), and is interested in having a market participation in as many categories as possible. In the case of the libraries:

$$
\sum_{f=1} \sum_{i} S U_{i f} \leq 0,3 * \sum_{f} \sum_{i} S U_{i f}
$$

In order to optimize the process is necessary to have a proportion between the armory families and tables of $1: 1.5$

$$
1.5 * \sum_{f=2} \sum_{i} S U_{i f} \geq \sum_{f=3} \sum_{i} S U_{i f}
$$

The company has established the maximum sales of each item by using forecast marketing techniques. These potential sales per item give another group of constraints.

$$
S U_{i} \leq P S_{i}
$$

- Activation of shop floor assets.

In the case of machine 1 of sawing process these constraints is formulated as follows:

$$
o_{11} \leq 10 * y_{11}
$$

At the end of the first stage, the shop floor assets of the company are used and the products and quantities to be produced has been determined. Then, the lot size of these products has to be calculated in order to meet the monthly demand. This decision considers that the company works with a monthly production plan. The general formulation of the second stage (lot size decision) is the following. We have described the additional sets, parameters and variables from the first stage:

\section{Additional sets}

ITEM Portfolio of the selected items (in the first stage) of company, indexed by $i$

PERIODS Planning period times, indexed by $t$

\section{Additional parameters}

Demand $_{i t} \quad$ Quantity of $S U_{i}$ to be satisfied by the market in the period $t$ [unit / time]

$S C_{i}$

$C C_{i}$ index $_{i t}$

$S U_{i}$

$F O P C_{j}$ stage 1)

$s 0_{i}$

$b l 1_{i}$ Storage
Shortage cost of item $i$ [\$ / unit]

Carrying cost of item $i$ [\$ / unit]

Stationary index for the sales of item $i$ in period $t$

Quantity of item $i$ that the company sells for the time horizon $T$. This decision was taken in the first stage. (It becomes a parameter in the second stage)

Final overall capacity of process $j$ [units of time] (With the machines selected in

Initial shortage of item $i$ in period 1[units]

Initial inventory of item $i$ in period 1[units]

Storage capacity of the finished goods warehouse. 
Additional variables

$\begin{array}{ll}F S_{i t} & \text { Final shortage of item } i \text { in period } t \text { [units] } \\ Q_{i t} & \text { Quantity of item } i \text { that the company schedules in period } t \text { [units] } \\ F I_{i t} & \text { Final inventory of item } i \text { in period } t \text { [units] } \\ \operatorname{setup}_{i j} & \text { Set up time of item } i \text { in process } j \text { [units of time] } \\ w_{i t} & \text { Binary variable equal to } 1 \text { if the process set up time for item } i \text { in the period } t, 0 \\ \text { otherwise. } & \end{array}$

The objective function is stated as a maximization of the annual profit of the company as follows,

$$
\begin{aligned}
& \text { Annual Profit }=\sum_{i} \sum_{t}\left(\left[\left(F S_{i t-1}+\text { Demand }_{i t}-F S_{i t}\right) * S P_{i}\right]-\frac{\left(Q_{i t} * U C_{i}\right)}{\prod_{s}\left(1-\operatorname{deff}_{i s}\right)}-\left(F S_{i t} * S C_{i}\right)-\left(F I_{i} * C C_{i}\right)\right) \\
& \text { where: } \\
& \text { Demand }_{i t}=\text { index }_{i t} * \frac{S U_{i}}{12} \quad \forall i, t
\end{aligned}
$$

The incomes and expenditures depend of the items, the monthly demand, the batch size, the level of inventory, and the shortage for each period. Therefore, the monthly profit of item $i$ is obtained by the subtraction of the expenditures of the period from the incomes of the period. The annual profit is obtained by adding the monthly profit of the items; and the total profit is calculated by the sum of the annual profits of each item. The key factors of the second stage have been determined in the previous stage. At the second stage, the variables of decision are related to with the machines to be used, the amount of available time in each process and the annual demand for each item. The demand is converted into monthly horizon affecting its mean value by a stationary index. The proposed model considers shortage; therefore the available units for each period are not enough to satisfy the monthly requirements. In case that in the period $t$ the available product is less than the monthly requirements, the sales in that particular period be equal to the available products. The units of item $i$ sold in month $t\left(\right.$ Sales $\left._{i t}\right)$ are:

$$
\text { Sales }_{i t}=F S_{i t-1}+\text { Demand }_{i t}-F S_{i t}
$$

We have defined the Sales $i t$ by considering that shortage is allowed. Indeed, the available product for each period $t$ is given by:

$$
Q_{i t}+F I_{i t-1}
$$

Moreover, the monthly requirements are given by:

$$
F S_{i t-1}+\text { Demand }_{i t}
$$

The sales for each period are equal to the available products. In this particular case the value of $F S_{i t}$ indicates the additional units that the company must sell, i.e. the lack of inventory. Additionally, if the available units are greater than the requirements, the units sold are the same as the requirements, and the value of $F S_{i t}$ is zero. This type of formulation is important also in cases where the products have different sale prices at different periods of the year. This objective function of the second stage is subject to the following constraints:

- Capacity of the different processes:

$$
\sum_{i}\left(\left(\operatorname{setup}_{i j} * w_{i t}\right)+\left(s t_{i j} * Q_{i t} / \prod\left(1-\operatorname{deff} f_{i j}\right)\right)\right) \leq \frac{F O P C_{j}}{12} ; \quad \forall j
$$


This set of constraints control the capacity of each process. In particular, it is only possible to use a maximum amount of time. The machines selected for each process at the first stage give this available time. If a lot of the product $i$ is manufactured for this period, this constraint guarantees that the set up time consumes part of the available time of the stage.

- Production balance:

For the first period this constraints could be expressed as:

$$
b l 1_{i}+Q_{i 1}+F S_{i 1}=\text { Demand }_{i 1}+F I_{i 1}+s 0_{i} \quad \forall i
$$

In general, for the other periods it is expressed as:

$$
F I_{i t-1}+Q_{i t}+F S_{i t}=\text { Demand }_{i t}+F I_{i t}+F S_{i t-1} \quad \forall i, t
$$

For the period 12, shortage is allowed:

$$
F S_{i 12} \leq 0,2 * \text { Demand }_{i 2} \quad \forall i
$$

In particular, the way to reduce the overall capacity of the different processes by the setup time affects the processes capacity at the second stage. Indeed, the sum of $Q_{i t}$ is less than the expected sales. There are two ways to handle this:

- Manage the information of the first stage as proportions and include a constraint of the second stage that forces the model to meet this proportion for each product of the portfolio.

- Allow a certain amount of shortage for all items in the last period. Therefore, the model considers the decisions of which product (or products) contributes less to the profit generation and assigns a value of shortage to those products. In particular, for the products that make a greater contribution to profit generation, the sum of $Q_{i t}$ meet the expected sales, i.e. the sum of $Q_{i t}$, is less than the expected sales for that item.

- Activation of set up time of item $i$ in period $t$ :

$Q_{i t} \leq 1000000 * w_{i t} \quad \forall i, t$

This constraint controls the assignation of the set up time.

- Space constraint:

$$
\sum_{i} F I_{i t} \leq \text { storage } \forall t
$$

This constraint assures that the space needed to keep the inventory in each period $t$ fits the space available of the finished goods warehouse.

\section{Solutions strategy: Sample Average Approximation (SAA)}

The proposed stochastic model has been solved by using the Sample Average Approximation (SAA) technique. According to Paz et al. (2015), the SAA algorithm is summarized in 4 steps:

i. Generate $S$ independent samples of size $N$ each, for $s=1, \ldots, S$ for each sample solve the corresponding SAA problem. 


$$
\max _{w \in W}\left\{c^{T} w+\frac{1}{N} \sum_{n=1}^{N} Q\left(w, \xi_{s}^{n}\right)\right\}
$$

For each $s$, it is possible to obtain the optimum value and the corresponding optimal solution, $v_{\mathrm{N}}$ and $\hat{y}_{\mathrm{N}}$.

ii. Calculate the following statistical indicators:

$$
\begin{aligned}
& \bar{v}_{N, S}=\frac{1}{S} \sum_{S=1}^{S} v_{N}^{S} \\
& \sigma_{\bar{v}, N, S}^{2}=\frac{1}{(S-1) S} \sum_{S=1}^{S}\left(v_{N}^{S}-\bar{v}_{N, S}\right)^{2}
\end{aligned}
$$

The value of $\bar{v}_{N, S}$ provides a statistical lower bound of the real optimal $(v *)$ of the original problem, while Eq. (22) is an estimator of its variance.

iii. Select a feasible solution $\bar{w} \in \mathrm{W}$ of the real problem, using as example the best of solutions $\widehat{w}_{N}^{S}$ calculated in Eq. (20). Calculate the objective function value of $(\overline{\mathrm{w}})$, using Eq. (23).

$$
\tilde{f}_{N^{\prime}}(\bar{w})=c \bar{w}+\frac{1}{N^{\prime}} \sum_{n=1}^{N^{\prime}} Q\left(\bar{w}, \xi^{n}\right)
$$

In Eq. (23), $\left(\xi_{j}^{1}, \ldots, \xi_{j}^{N^{\prime}}\right)$ is a sample of size $N^{\prime}$ which is independent of the samples used in step 1. In general, it is usual to take a value $N^{\prime}$ much greater than $N$. Since the samples are independent and identically distributed, the variance of Eq. (23) can be expressed as follows:

$$
\sigma_{N^{\prime}}^{2}(\bar{w})=\frac{1}{\left(N^{\prime}-1\right) N^{\prime}} \sum_{j=1}^{N^{\prime}}\left[c \bar{w}+Q\left(\bar{w}, \xi^{n}\right)-\hat{f}_{N^{\prime}}(\bar{w})\right]^{2}
$$

In this case, since the problem to be solved is maximization, it is natural to choose $\bar{w}$ with the highest estimated objective function value $\tilde{f}_{N^{\prime}}(\bar{w})$.

iv. Calculate an estimate of the optimality gap of solution $\bar{w}$ by using the results obtained in steps 2 and 3 as follows:

$$
\operatorname{gap}_{S, M, N}(\bar{w})=\tilde{f}_{N^{\prime}}(\bar{w})-\bar{v}_{N, S}
$$

The estimated gap variance is calculated as follows:

$$
\sigma_{\text {gap }}^{2}=\sigma_{N^{\prime}}^{2}(\bar{w})+\sigma_{\bar{v}, N, S}^{2}
$$

The SAA algorithm developed in this study is based on the steps proposed by Paz et al. [25]. This optimization algorithm must to solve initially a sample of $M$ problems of the deterministic model each one with $S$ demand scenarios generated by Monte Carlo Simulation. The indicators of the SAA is calculated for the supply network design for $N^{\prime}=3 S$. If the stop criteria ( $g a p \leq 5 \%$ ) is not met, the algorithm is repeated with $M=2 M$ until find an optimal solution. 


\section{Results Analysis}

The optimization process was performed generating 600 scenarios for the first stage and 300 scenarios for the second stage. A branch bound algorithm has been performed for each scenario. These scenarios have been grouped in samples of 20 . Then the number of samples performed was 30 . The proposed stochastic model has been solved using CPLEX 12.1. After performing some preliminary tests, it became clear that the ideal runtime for CPLEX is 1 hour, due to the change of the objective function was of $0.01 \%$, when increasing the time limit from 1 hour to 2 hours, and from 2 hours to 7 hours of runtime the objective function remained constant.

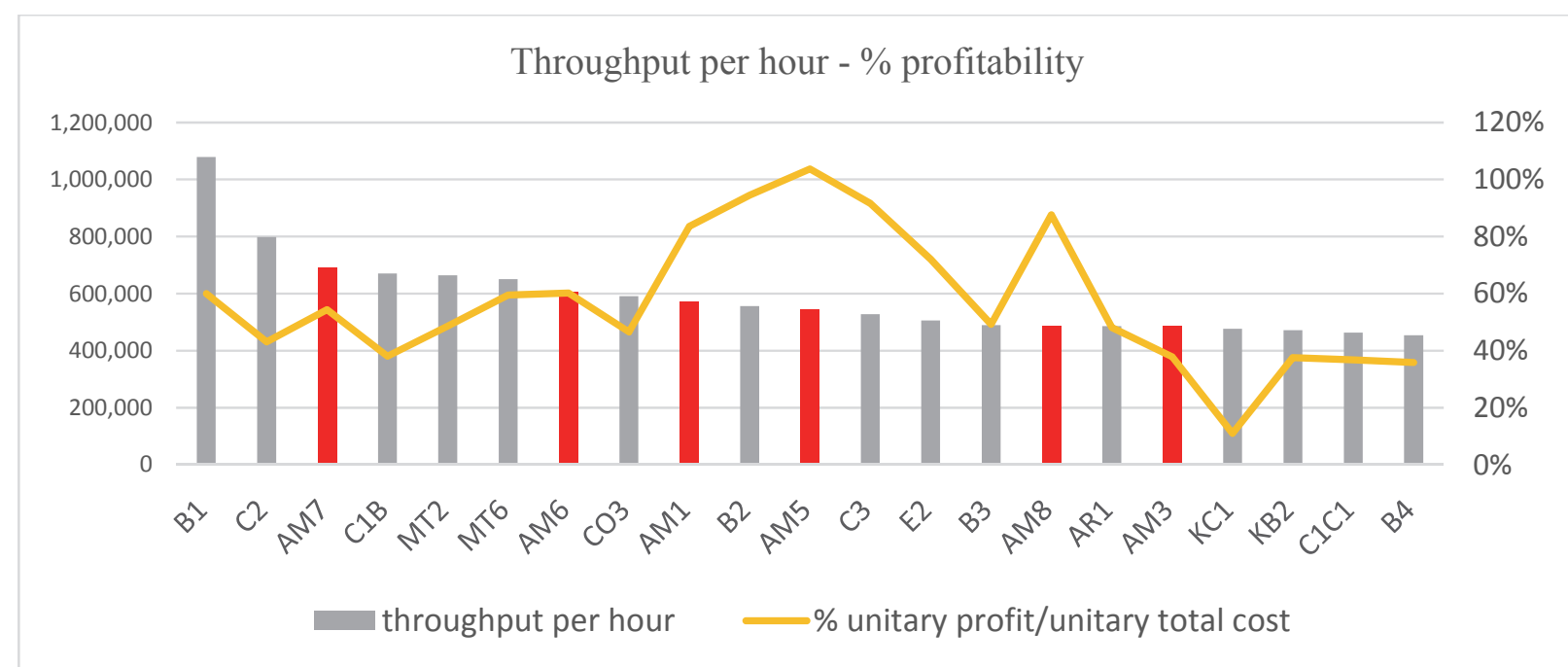

Fig. 1A. Items throughput and profitability, ordered in throughput descending trend

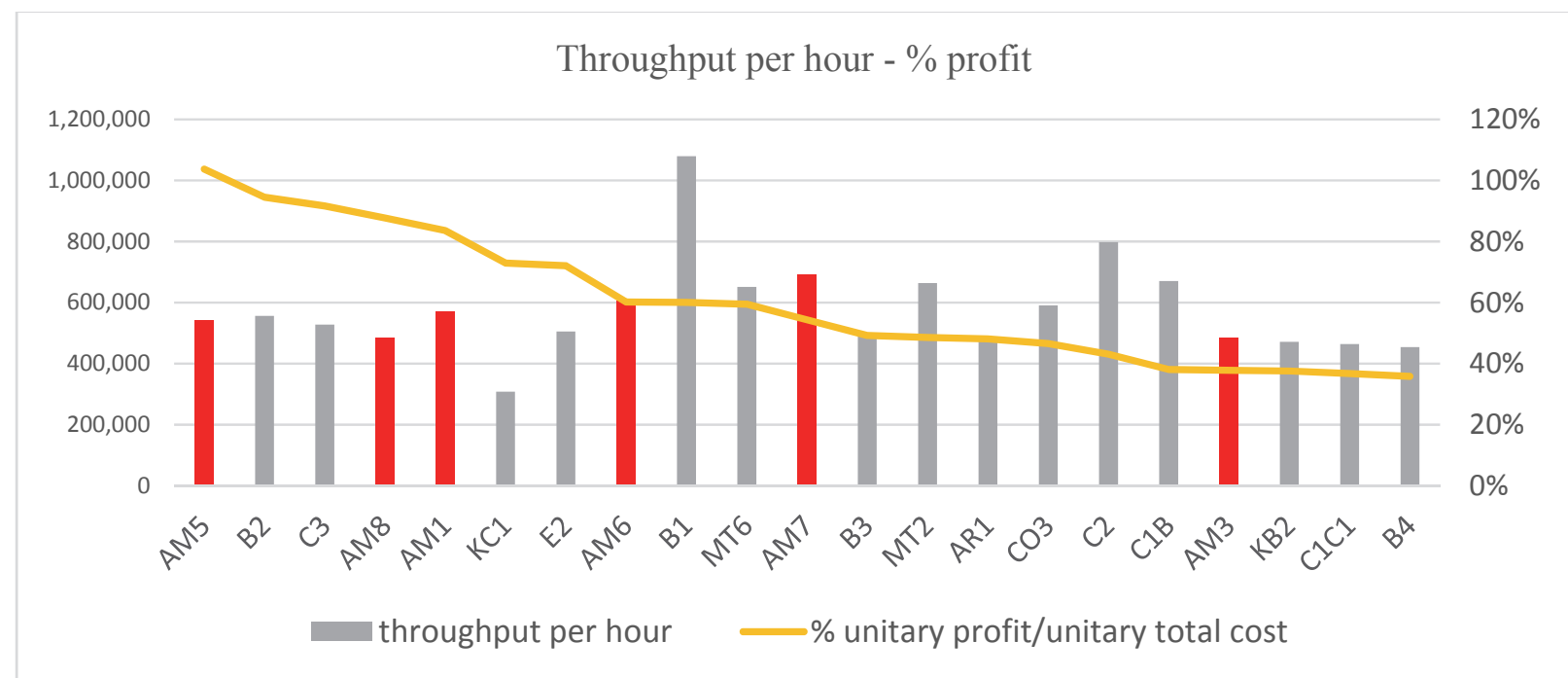

Fig. 1B. Items throughput and profit, ordered in profitability descending trend

The first stage of the optimization indicates the items that contribute to the maximization of the EVA. In addition, the results of the first model allow analyzing the rest of the portfolio of products taking into account the references, which reduce less the EVA of the company. 
Nevertheless, the scenario with the higher value of the objective function activates and chooses the machines and items the company should produce. These items and machines are used in the stage 2 (lot sizing). It is very important to analyze the items chosen in this first stage. Commonly the criteria used for the lot size determination are lower cost, higher throughput and higher unitary profitability ( $\%$ unitary profit/unitary total cost). In this work, the proposed objective function couldn't found any dominance of these criteria.

Fig. 1A and Fig. 1B show the throughput of products and the profitability for some items respectively. Fig. 1A shows the items in a descending trend of throughput per hour, while Fig. 1B shows the same items of Fig. 1A considering unitary profitability (\% unitary profit/unitary total cost) ordering them in a descending trend. This is an important result because shows a different way to select the mix of products for the company. On Figs. 1A and 1B items included in the armoire product family are highlighted in red. On Fig. 1A it can be observed that the armoires with the higher throughput are AM6, AM7 and AM1. And the armoires with the higher profitability (Fig. 1B) are AM5, AM8 and AM1. Nevertheless the selected armoires in the product selection are AM6, AM7, and AM8; because these are the products that contribute in a better way to EVA generation. Similar behavior can be observed among the other product families.

In particular, we have used the EVA as criterion, which is not commonly used. The EVA considers a holistic point of view considering costs, productivity and profitability. The constraint that forces the company not concentrate its production and sales in a few items, also forces to the model to activate some other wildcard items depending on the variability for each scenario.

\section{Table 1}

Results of the proposed stochastic model. Source: Owner

\begin{tabular}{ccccc}
\hline & \multicolumn{4}{c}{ Results of the Proposed Model } \\
\cline { 2 - 5 } & Final Inventory & Batch Size & Number of batches & Shortage \\
\cline { 2 - 5 } & Mean Value (Monthly) & Mean Value & (Year) & Mean (Monthly) \\
\hline AM6 & 252.16 & 2179.6 & 9.84 & 3.75 \\
AM7 & 308.63 & 1863.78 & 8.56 & 3.58 \\
AM8 & 205.22 & 990.6 & 7.23 & 18.79 \\
B1 & 699.04 & 2507.43 & 4.35 & 56.77 \\
B2 & 362.81 & 1979.69 & 5.64 & 95.77 \\
B3 & 708.36 & 3416.51 & 3.98 & 238.84 \\
B4 & 552.89 & 3180.83 & 4.06 & 269.75 \\
C2 & 480.47 & 2324.05 & 2.67 & 132.05 \\
CO3 & 578 & 3754.08 & 4.24 & 348.72 \\
CT1 & 337.43 & 1920.88 & 3.35 & 195.05 \\
CV2 & 87.76 & 1010.73 & 4.08 & 265.46 \\
E2 & 57.73 & 1184.86 & 11.01 & 91.09 \\
MT1 & 214.68 & 5245.3 & 5.53 & 1537.4 \\
MT2 & 312.09 & 1705.57 & 7.85 & 57.29 \\
MT4 & 327.71 & 1615.93 & 2.01 & 146.96 \\
MT6 & 367.33 & 2516.46 & 5.56 & 242.41 \\
KB2 & 661.38 & 3650.08 & 4.44 & 264.03 \\
\hline
\end{tabular}

Table 1 shows a summary for the results of the 300 scenarios performed. On this table a comparison between selected items AM6 and CT1 can be performed. AM6 is scheduled an average of 9.84 times in a year. On the other hand CT1 is scheduled only 3.35 times per year. This happens because AM6 is a very important item for EVA generation and additionally it has a high sale price and high unitary cost. Scheduling this valuable items many times the solver tries to minimize their inventory and shortage cost. This issue can be noticed also when checking the mean shortage and the mean inventory of the two references. CT1 is not so important for EVA generation (wildcard item) therefore falling into carrying and 
shortage cost costs in these references is not so critical than falling into these costs with EVA relevant items such as AM6. The proposed model can be applied both for MTS (make to stock) and MTO (make to order) systems by manipulating the shortage cost, the carrying cost, and variables such as shortage, final inventory and warehouse available space. Another important issue is that the maximization of the EVA as the objective function, allows the decision maker to involve costs, earnings, profits and productivity together.

\section{Concluding remarks and future works}

In this study, we propose a Stochastic Mixed Integer Linear Programming Model (SILP) for the product mixing and lot-sizing problem. The decisions of the stochastic model are defined in two steps by considering variability of the demand. It is proposed as objective function of the SILP model, the maximization of EVA, the latter is defined as the economic value added generated by the company. The solution strategy used for the SILP model solution is known as Sample Average Approximation (SAA). The results of the application of this methodology show that the proposed approach is an effective decision support tool of product mix and lot sizing problems by considering the expected economic contribution of products and variability of the demand. In addition, we have demonstrated that the methodology SAA provides near-optimal solutions for linear stochastic programming problems with small sample sizes on production problems. Dynamic aspects of the problem, which help to make decisions according to the demand seasonality and the variability of the prices, could be considered as future research work. In addition, decisions of scheduling of products and decisions of space constraints for working process must be taking into account. Finally, applicability of other methods for solving stochastic linear optimization models and other real cases such as companies with different production systems could be considered as extensions of this paper.

\section{References}

Absi, N., \& Kedad-Sidhoum, S. (2008). The multi-item capacitated lot-sizing problem with setup times and shortage costs. European Journal of Operational Research, 185(3), 1351-1374.

Ahmed, S., Tawarmalani, M., \& Sahinidis, N. V. (2004). A finite branch-and-bound algorithm for twostage stochastic integer programs. Mathematical Programming, 100(2), 355-377.

Alejandro, G. H. J.W Escobar, \& Álvaro, F. C. (2013). A Multi-Product Lot-Sizing Model for a Manufacturing Company. Ingeniería Investigación y Tecnología, 14(3), 413-419.

Azaron, A., Tang, O., \& Tavakkoli-Moghaddam, R. (2009). Dynamic lot sizing problem with continuous-time Markovian production cost. International Journal of Production Economics, 120(2), 607-612.

Escobar J.W. (2012). Rediseño de una red de distribución con variabilidad de demanda usando la metodología de escenarios. Revista Facultad de Ingeniería UPTC, 21(32), 9-19.

Escobar, J. W. (2009). Modelación y Optimización de diseño de redes de distribución de productos de consumo masivo con elementos estocásticos. Proceedings of XIV Latin American Summer Workshop on Operations Research (ELAVIO), El Fuerte, México.

Escobar J.W., Bravo, J.J., \& Vidal, C.J. (2012). Optimización de redes de distribución de productos de consumo masivo en condiciones de riesgo. Proceedings of XXXIII Congreso Nacional de Estadistica e Investigación Operativa (SEIO), Madrid, Spain.

Escobar, J. W., Bravo, J. J., \& Vidal, C. J. (2013). Optimización de una red de distribución con parámetros estocásticos usando la metodología de aproximación por promedios muéstrales. Ingeniería y Desarrollo, 31(1), $135-160$.

Fleischmann, B. (1990). The discrete lot-sizing and scheduling problem. European Journal of Operational Research, 44(3), 337-348.

Haksever, C., \& Moussourakis, J. (2008). Determining order quantities in multi-product inventory systems subject to multiple constraints and incremental discounts. European Journal of Operational Research, 184(3), 930-945. 
Karimi, B., Ghomi, S. F., \& Wilson, J. M. (2003). The capacitated lot-sizing problem: a review of models and algorithms. Omega, 31(5), 365-378.

Kleywegt, A. J., Shapiro, A., \& Homem-de-Mello, T. (2002). The sample average approximation method for stochastic discrete optimization. SIAM Journal on Optimization, 12(2), 479-502.

Lin, C. H. E. N., \& QIAO, Z. L. (2010). What influence the Company's Economic Value Added? Empirical Evidence from China's Securities Market. Management Science and Engineering, 2(1), 6776.

Mabin, V. J., \& Gibson, J. (1998). Synergies from spreadsheet LP used with the theory of constraintsa case study. Journal of the Operational Research Society, 49(9), 918-927.

Mafla I., Escobar J.W., (2015). Rediseño de una red de distribución para un grupo de empresas que pertenecen a un holding multinacional considerando variabilidad de la demanda. Revista de la Facultad de Ingeniería U.C.V., 30(1), $37-48$.

Marshall, A. (1890). Principles of Political Economy. Maxmillan, New York.

Niebles-Atencio, F. N., \& Niera-Rodado, D. N. (2016). A Sule's method initiated genetic algorithm for solving QAP formulation in facility layout design: A real world application. Journal of Theoretical and Applied Information Technology, 84(2), 157.

Paz, J. C., Orozco, J. A., Salinas, J. M., Buriticá, N. C., \& Escobar, J. W. (2015). Redesign of a supply network by considering stochastic demand. International Journal of Industrial Engineering Computations, 6(4), $521-538$.

Ray, R. (2001). Economic value added: Theory, evidence, a missing link. Review of Business, 22(1/2), 66.

Rizk, N., \& Alain, M. (2001). Supply chain flow planning methods: a review of the lot-sizing literature. Canada: Universite Laval Canada and Centor. Centre de recherche sur les technologies de l'organisation réseau (CENTOR)

Rizk, N., Martel, A., \& Ramudhin, A. (2006). A Lagrangean relaxation algorithm for multi-item lotsizing problems with joint piecewise linear resource costs. International Journal of Production Economics, 102(2), 344-357.

Santoso, T., Ahmed, S., Goetschalckx, M., \& Shapiro, A. (2005). A stochastic programming approach for supply chain network design under uncertainty. European Journal of Operational Research, 167(1), 96-115.

Singh, T., \& Mehta, S. (2012). EVA VS Traditional Accounting Measures: A Pre-Recession Case Study of Selected IT Companies. International Journal of Marketing and Technology, 2(6), 95-120.

$\mathrm{Su}, \mathrm{C}$. T., \& Wong, J. T. (2008). Design of a replenishment system for a stochastic dynamic production/forecast lot-sizing problem under bullwhip effect. Expert Systems with Applications, 34(1), 173-180.

Van Eijs, M. J. G., Heuts, R. M. J., \& Kleijnen, J. P. C. (1992). Analysis and comparison of two strategies for multi-item inventory systems with joint replenishment costs. European Journal of Operational Research, 59(3), 405-412.

Van Hoesel, S., Kuik, R., Salomon, M., \& Van Wassenhove, L. N. (1994). The single-item discrete lot sizing and scheduling problem: optimization by linear and dynamic programming. Discrete Applied Mathematics, 48(3), 289-303.

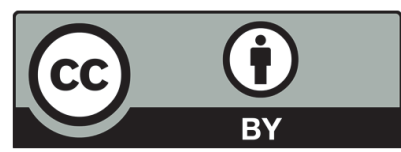

C 2016 by the authors; licensee Growing Science, Canada. This is an open access article distributed under the terms and conditions of the Creative Commons Attribution (CCBY) license (http://creativecommons.org/licenses/by/4.0/). 